J. Asiat. Soc. Bangladesh, Sci. 40(2): 319-323, December 2014

- Short communication

\title{
PESTICIDE RESIDUES IN POND WATER SAMPLES FROM COASTAL AREA OF BANGLADESH
}

\author{
M. AMIN UDDIN' ${ }^{\prime}$, M.A.Z. CHOWDHURY, M, A. RAHMAN, \\ M. H. RASHID AND M. K. ALAM \\ Institute of Food and Radiation Biology, Atomic Energy Research Establishment, \\ Gonakbari, Savar, GPO Box-3787, Dhaka-1000
}

Water samples collected from twenty five ponds of coastal area were analyzed by HPLC for the presence of organophosphorus, pyrethroid and carbamate pesticide residues. The results reflected slight contamination of some of the water samples with residues of diazinon, chlorpyriphos (organophosphorus insecticide), carbaryl and carbofuran (carbamate insecticide). The concentration of diazinon and chlorpyriphos ranged from $2.31 \mu \mathrm{g} / \mathrm{L}$ to $5.60 \mu \mathrm{g} / \mathrm{L}$ and 0.0 to $3.80 \mu \mathrm{g} / \mathrm{L}$ respectively. Among carbamate pesticides, carbofuran identified in two samples, ranging from 1.40 to $3.71 \mu \mathrm{g} / \mathrm{L}$, carbaryl was detected in two of the samples which ranged from 1.32 to $6.40 \mu \mathrm{g} / \mathrm{L}$, and pyrethroid (cypermethrin) was not detected in any of the samples. However, the residue level was also within the acceptable ranges according to the WHO guideline value (1993) of water quality. But, its presence in surface water as WHO-recommended limits is a matter of concern.

In Bangladesh consumption of pesticides has been increased with the introduction of high yielding varieties of rice in recent years. But, the widely cultivated high yielding variety is highly vulnerable to pests and diseases, and $40 \%$ of the crop loss can be attributed to attack by pests and insects in Bangladesh which is a significant loss (Bagchi, et al. 2008). So, the use of pesticide is now an integral part of agriculture for pest control.

More than 100 species of insects, 600 weed species, 1500 plant diseases and 1500 species of nematodes are being controlled by pesticide (Brady 1990). As a result, the production of improved variety of rice has significantly increased in recent years. Although pesticide is beneficial for pest control, it also poses a harmful effect to our environment such as the pollution of surface and ground water. After application of pesticide in the crop field it is degraded in the soil by the soil microorganism to some extent but many of the toxic pesticides are transported into surface and ground water by agricultural run off rain water from the crop field. Ultimately, the surface and ground water may be highly contaminated due to this agricultural run off pesticide (Bagchi, et al. 2008).

\footnotetext{
' Corresponding author: Email: aminifrb@yahoo.com
} 
In general, indiscriminate dumping of agricultural wastes, industrial effluents, domestic sewage, navigational discharges etc. are responsible for increasing the heavy metals and pesticides content in surface water (Zingde, et al. 1983). When entering into the soil, pesticides may be taken up by plants or degraded; but they may also be transported through the unsaturated zone to groundwater (Miglioranza, et al. 1999). In most cases, water carries or translocates the pesticides from one place to another. Consequently, considerable levels of organochlorines have been detected in air, soil, groundwater, plants, and food chains and finally reach humans directly and or indirectly but in biological systems it may be accumulated and be magnified and create health hazards (Chowdhury, et al. 2003). But present measures in Bangladesh are inadequate and the existing rules are rarely implemented, allowing sale of unregistered pesticides and misuse by farmers. Very few works in pesticide contamination of coastal area have been conducted in Bangladesh but no significant record is available. Therefore, this work was designed to understand the magnitude of pesticide residue problems and to find out the residue level of commonly used pesticides and their degraded products in coastal water

Analytical grade hexane (Merck, Germany); acetone (extra pure, BDH, England); anhydrous Sodium Sulphate (Merck, Germany); Florisil (Magnesium Silicate, Sigma, USA, mesh 60-100); and diethyl ether(BDH, England), Rotary vacuum evaporator (Type -350 , USA); HPLC-High Performance Liquid Chromatograph (SHIMADZU, Japan), Detector- Photo Diode Array (PDA) were used.

Water samples were collected in glass containers from some selected ponds of coastal area (Noakhali and Feni ) of Bangladesh. Samples were then brought to the laboratory, Institute of Food and Radiation Biology, Atomic Energy Research Establishment, Gonakbari, Savar, as quickly as possible and kept in freezing condition until extraction to avoid degradation. Extraction of water sample $(500 \mathrm{~mL}$ each) was performed with 100 $\mathrm{mL}$ double distilled hexane in a separatory funnel with shaking for 5 minutes. Hexane extract was separated and collected in evaporating flasks. Two further extractions with $25-\mathrm{mL}$ hexane were done. The combined hexane extract was treated with $5.00-\mathrm{g}$ anhydrous sodium sulphate to remove traces of water. The water free extract was evaporated to a small volume (approx. $1 \mathrm{~mL}$ ) and transferred to a glass-stopered test tube followed by complete evaporation of solvent under a mild stream of nitrogen.

The extract was subjected to clean-up using florisil column chromatography (DFG Manual 1987). The top $1.5 \mathrm{~cm}$ of the florisil column was packed with anhydrous sodium sulphate. Elution was carried out with $2 \%$ diethyl ether in hexane $(5.00 \mathrm{~mL} / \mathrm{min})$. The eluate was concentrated in a rotary vacuum evaporator and solvents were completely removed under mild nitrogen flow. The evaporated sample was dissolved in acetonitrile and then made to volume $1.00 \mathrm{~mL}$ in a volumetric flask for high performance liquid chromatography (Uddin, et al. 2013). 
Injections of the aliquots (usually $20 \mu \mathrm{L}$ ) were done by micro syringe into HPLC. Identification of the pesticide was carried out in relation to the retention time of the pure analytical standard (Fig.1) supplied by International Atomic Energy Agency (IAEA). Quantification was made with a standard curve of the relevant (standard) pesticide and analysis was done by HPLC (Fig. 2).

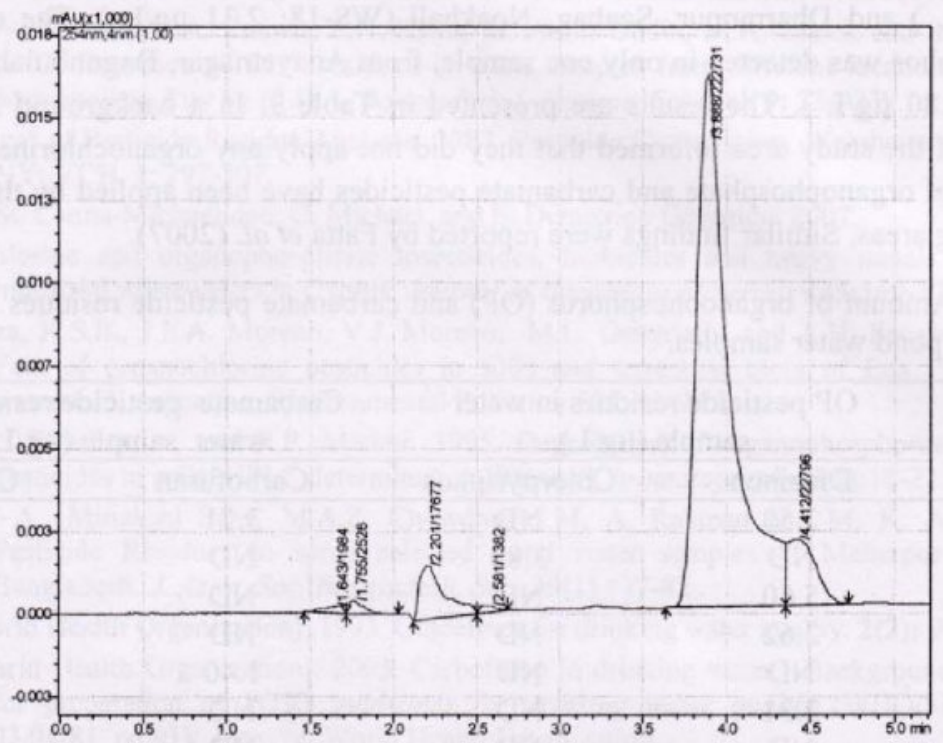

Fig. 1. A Typical Chromatogram of Standard Carbofuran $(100 \mu \mathrm{g} / \mathrm{mL})$, Retention Time $(\mathrm{RT})=3.888 \mathrm{~min}$. Limit of detection (LOD) was $0.01 \mu \mathrm{g} / \mathrm{mL}$.

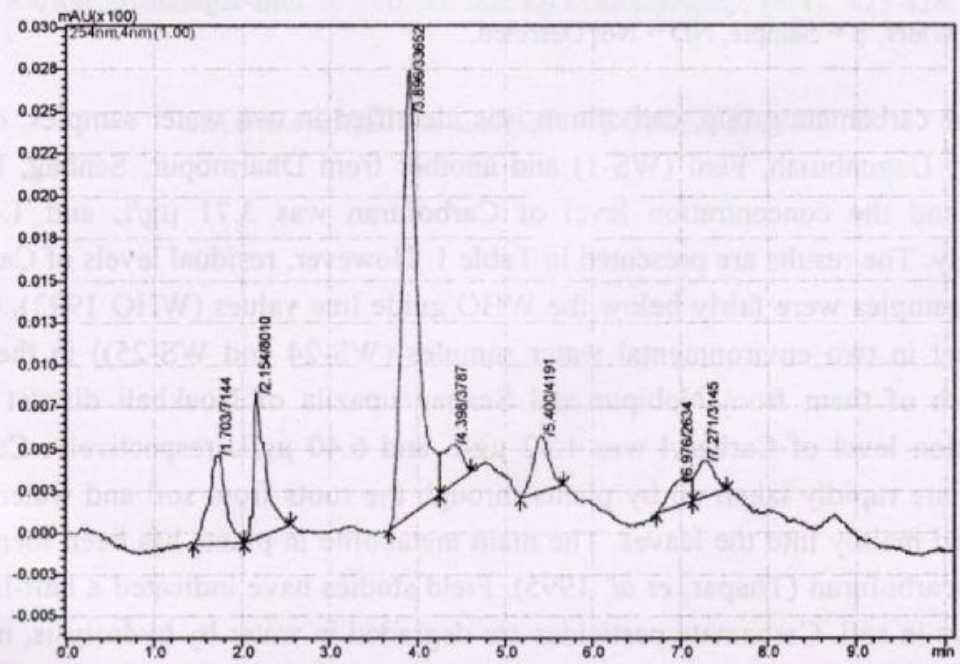

Fig. 2. A Typical Chromatogram of Water Sample 17 Showing the Presence of Carbofuran $(1.40 \mu \mathrm{g} / \mathrm{L}), \mathrm{RT}=3.896 \mathrm{~min}$. 
Twenty five water samples collected from the most vulnerable sites of coastal region of Bangladesh were analyzed for the presence of pesticide residues According to the results of this study, diazinon was found to be present in four water samples; one from West Kazirkhil, Senbag upazilla (WS-01; $2.50 \mu \mathrm{g} / \mathrm{L}$ ), another from Anayetnagar, Dagonbuiah, Feni (WS-10; $5.60 \mu \mathrm{g} / \mathrm{L}$ ), and the last two from Ramnager, Dagonbuiah, Feni (WS-13; $2.62 \mu \mathrm{g} / \mathrm{L}$ ) and Dharmopur, Senbag, Noakhali (WS-18; $2.31 \mu \mathrm{g} / \mathrm{L}$ ). The residue of chlorpyriphos was detected in only one sample, from Anayetnagar, Dagonbuiah and Feni (WS-8; $3.80 \mu \mathrm{g} / \mathrm{L}$ ). The results are presented in Table 3. In a background study, the farmers of the study area informed that they did not apply any organochlorine pesticide but a lot of organophosphate and carbamate pesticides have been applied by them in the cultivating areas. Similar findings were reported by Fatta et al. (2007).

Table 1. Amount of organophosphorus (OP) and carbamate pesticide residues in coastal pond water samples.

\begin{tabular}{ccccc}
\hline \multirow{2}{*}{$\begin{array}{c}\text { Sample } \\
\text { No }\end{array}$} & \multicolumn{2}{c}{$\begin{array}{c}\text { OP pesticide residues in water } \\
\text { sample }(\mu \mathrm{g} / \mathrm{L})\end{array}$} & $\begin{array}{c}\text { Carbamate pesticide residues in } \\
\text { water sample }(\mu \mathrm{g} / \mathrm{L})\end{array}$ \\
\cline { 2 - 5 } & Diazinon & Chlorpyriphos & Carbofuran & Carbaryl \\
\hline WS1 & 2.50 & ND & 3.71 & ND \\
WS8 & ND & 3.80 & ND & ND \\
WS10 & 5.60 & ND & ND & ND \\
WS13 & 2.62 & ND & ND & ND \\
WS17 & ND & ND & 1.40 & ND \\
WS18 & 2.31 & ND & ND & ND \\
WS24 & ND & ND & ND & 1.32 \\
WS25 & ND & ND & ND & 6.40 \\
\hline
\end{tabular}

Note: $\mathrm{W}=$ Water, $\mathrm{S}=$ Sample, $\mathrm{ND}=$ Not Detected.

Among the carbamate group, carbofuran was identified in two water samples; one from Ramnager, Dagonbuiah, Feni (WS-1) and another from Dharmopur, Senbag, Noakhali (WS-17) and the concentration level of Carbofuran was $3.71 \mu \mathrm{g} / \mathrm{L}$ and $1.40 \mu \mathrm{g} / \mathrm{L}$ respectively. The results are presented in Table 1. However, residual levels of Carbofuran in all the samples were fairly below the WHO guide line values (WHO 1993). Carbaryl was present in two environmental water samples (WS-24 and WS-25)) in the present study. Both of them from Nobipur and Senbag upazila of Noakhali district and the concentration level of Carbaryl was $1.32 \mu \mathrm{g} / \mathrm{L}$ and $6.40 \mu \mathrm{g} / \mathrm{L}$ respectively. Carbamate pesticides are rapidly taken up by plants through the roots from soil and water and are translocated mainly into the leaves. The main metabolite in plants has been identified as 3-hydroxycarbofuran (Thapar, et al. 1995). Field studies have indicated a half-life of 26 to 110 days in soil. Carbamate pesticides are degraded in water by hydrolysis, microbial decomposition and photolysis (WHO 2003 and Thapar, et al. 1995). 


\section{References}

Bagchi, S., A.K. Azad, M. Alamgir, Z. Chowdhury, M. Amin Uddin, Sharif M. Al-Reza and Atiqur Rahman. 2008. Quantitative Analysis of Pesticide Residues in some Pond water samples of Bangladesh. Asian Journal of water, Environment and Pollution, 6: 27-30.

Brady, N. C. The Nature and Properties of Soil. $10^{\text {th }}$ edition. Macmillan Inc., U.S.A (1990).

Chowdhury, M.A.Z., M.A. Zaman, Z.H. Khan, M. Amin Uddin, M.A. Malek and S. M. Ullah. 2003. Detection of DDT residues in water samples from different locations of Dhaka Metropolitan City by ELISA, Bangladesh J. Environ. Sci. Vol. 9: 234-239.

DFG Manual of Pesticide Residue Analysis. 1987. Pesticide Commission, Weinheim, New York, NY: VCH. 1: 297-307.

Fatta, D., St. Canna-Michaelidou, C, Michael. and E. Demetriou Georgiou. 2007.

Organochlorine and organophosphoric insecticides, herbicides and heavy metals residue in industrial wastewaters in Cyprus. Journal of Hazardous Materials 145:169-179.

Miglioranza, K.S.B., J.E.A. Moreno, V.J. Moreno, M.L. Osterrieth and A.H. Escalanate. 1999. Fate of organochlorine pesticides in soils and terrestrial biota of Los Padres pond watershed. Argentina, Environmental Pollution 105: 91-99.

Thapar, S., Bhushan, r., and R.P. Mathur. 1995. Degradation of organophosphprus carbamate pesticides in soils: HPLC determination. Biomed Chromatography 9(1):18-22.

Uddin M. A., Minakshi Saha, M.A.Z. Chowdhury, M, A. Rahman and M. K. Alam. 2013. Pesticide Residues in some selected pond water samples of Meherpur region of Bangladesh. J. Asiat. Soc. Bangladesh, Sci., 39(1): 77-82 .

WHO (World Health Organization). 1993. Guidelines for drinking water quality. 2(2): 940-949.

WHO (World Health Organization). 2003. Carbofuran in drinking water. Background document for preparation of WHO guidelines for drinking water quality (WHO/SDE/ WSH/ 03.04/81, pp.01). Geneva, World Health Organization.

Zingde M.D., and S.Y.S., Singbal. 1983. Characteristics of near shore water in the Binge Bay, Karwar. Mahasagar-Bull. of National Inst. Of Oceanography, 16(4): 423-428.

(Received revised manuscript on 12 October 2014) 